\title{
Ciprofloxacin self-dissolvable Soluplus based polymeric films: a novel proposal to improve the management of eye infections
}

\author{
Antonio J. Guillot ${ }^{1} \cdot$ Dimitris Petalas $^{1} \cdot$ Pari Skondra $^{1} \cdot$ Hortensia Rico ${ }^{2} \cdot$ Teresa M. Garrigues $^{1} \cdot$ Ana Melero $^{1}(\mathbb{C}$
}

Accepted: 14 December 2020 / Published online: 2 February 2021

(c) Controlled Release Society 2021

\begin{abstract}
Infections of the eye are among the leading causes of vision impairment and vision loss worldwide. The ability of a drug to access the anterior parts of the eye is negligible after systemic administration. Effective drug delivery to the eye is a major challenge due to the presence of protective mechanisms and physiological barriers that result in low ocular availability after topical application. The main purpose of this work was the improvement of the corneal and conjunctival permeation of the antibiotic Ciprofloxacin, a wide spectrum antibiotic used for the most common eye infection, using a self-dissolving polymeric film. Films were prepared by the solvent casting technique, using polyvinyl caprolactam-polyvinyl acetate-polyethylene glycol graft co-polymer (Soluplus), polyvynyl alcohol, and propylene glycol. Films were homogeneous in drug content and thickness, as demonstrated by adapting the Swiss Roll technique followed by microscopy observation. These films proved in vitro to control the release of the Ciprofloxacin. Ex vivo permeability studies using Franz diffusion cells and porcine cornea and sclera showed an effective permeability of the drug without inducing irritation of the tissues. Films swelled in contact with artificial tears forming an in situ gel over $20 \mathrm{~min}$, which will improve drug contact and reduce the need of multiple dosing. The antibiotic activity was also tested in vitro in five types of bacterial cultures, assuring the pharmacological efficacy of the films. The developed films are a promising drug delivery system to topically treat or prevent ocular infections.
\end{abstract}

Keywords Soluplus · Ocular films · Ciprofloxacin $\cdot$ Controlled release $\cdot$ Ocular permeability $\cdot$ Antibiotic efficacy

$\begin{array}{ll}\text { Abbreviations } \\ \text { CPX } & \text { Ciprofloxacin } \\ \text { CPXb } & \text { Ciprofloxacin base form } \\ \text { CPXs } & \text { Ciprofloxacin salt form } \\ \text { DMSO } & \text { Dimethyl sulfoxide } \\ \text { HEC } & \text { Hydroxy ethyl cellulose } \\ \text { HPMC } & \text { Hydroxy propyl methyl cellulose } \\ \text { LD } & \text { Limit of detection } \\ \text { LQ } & \text { Limit of quantification } \\ \text { PBS } & \text { Phosphate-buffered saline } \\ \text { PCL } & \text { Polycaprolactone }\end{array}$

Teresa M. Garrigues

teresa.garrigues@uv.es

Ana Melero

ana.melero@uv.es

1 Department of Pharmacy and Pharmaceutical Technology and Parasitology, University of Valencia, Avda. Vicente A. Estelles SN, Burjassot Valencia, Spain

2 Department of Microbiology and Ecology, University of Valencia, Avda. Vicente A. Estelles SN, Burjassot Valencia, Spain

$\begin{array}{ll}\text { PEG } & \text { Polyethylene glycol } \\ \text { PG } & \text { Propylene glycol } \\ \text { PVA } & \text { Polyvinyl alcohol } \\ \text { SD } & \text { Standard deviation } \\ \text { SI } & \text { Swelling index }\end{array}$

\section{Introduction}

The eye is a very sensitive organ, vulnerable to a wide variety of pathologies and accidents that may compromise its correct performance. Among the main diseases of the anterior eye segment are cataracts, dry eye, inflammatory processes, infections, and tumours. Infectious pathologies such as trachoma and corneal ulcers, glaucoma, agerelated macular degeneration, and diabetic retinopathy refer to the posterior eye segment. Some of them are the important causes of vision impairment worldwide [1].

The causative agents for infecting the eyes may range from microbes such as bacteria, viruses, fungi, and even parasites. An infection of the eye with such microbes requires immediate treatment as it may threaten normal 
vision. According to the cause and type of infection, medication may include different type of antibiotics [2]. Besides, antibiotics are also used for infection prophylaxis after surgery.

Commonly, the treatment of the anterior segment diseases requires that the drug either remains onto the eye surface to address surface-affecting diseases (i.e., certain infections or to stimulate tear production) or reaches the aqueous humour that bathes the anterior face of the crystalline lens. Since after systemic administration the ability of a drug to reach the anterior segments is nearly null, intense efforts for developing efficient topical ophthalmic formulations have been made during the last decades [3-5].

Despite the accessibility of the eye surface, drug delivery to the eye is a challenge, due to its anatomy, physiology, and biochemistry [6]. The main barriers to drug diffusion through the cornea include tear dilution, nasolacrimal drainage, blinking, low formulation volume, low residence time, and the corneal and conjunctival layers [7]. The application of a drop of a liquid or semisolid formulation is not an efficient way of administration to the eye. In situ forming gels have been suggested as an alternative to improve drug contact to the eye, reduce blurred vision, and decrease the tear production compared with ointments [8]. Another problem of traditional dosage forms is that coordination of patient nonblinking and application of the formulation while pressing the container may also be difficult for elderly patients, children, or persons affected of certain disabilities, what leads to a large imprecision in the dose administered $[9,10]$.

As another alternative to eye drops, ocular films have been developed to increase drug permanence on the eye. They are polymeric solid or semi-solid, thin, sterile films, which are placed onto the conjunctiva. With the convenience of direct application, these formulations display advantages, such as direct tissue contact for extended periods of time, along with sustained release [11] Due to the presence of polymers, the release pattern of drugs from the ocular films can be modelled in accordance with the type of drug, as well as a targeted delivery. The ideal mechanisms of drug release from these films are diffusion, osmosis, or bioerosion [12].

Polymeric films of Ciprofloxacin (CPX) for enhancement of posterior and anterior ocular segment delivery have not been reported until now. Hence, we developed and characterized self-dissolvable CPX films to improve drug contact with the cornea and to achieve a sustained release of the drug, while the film is slowly dissolved by the tears. Their dissolvability is an additional advantage, as they do not need to be removed after drug release. This new ocular film would use the solubility enhancement ability of Soluplus micelles, together with the prolonged contact time with the cornea and user-friendliness of a dry film. This novel formulation is inspired in the work of Alopaeous et al., who designed Soluplus-based films for buccal delivery of furosemide. The authors postulated that Soluplus present in the film will disperse and form micelles after application on a wet surface [13]. In the low volume of the tears, the Soluplus concentration is expected to be above the critical micellar concentration. A slow hydration and disintegration of the film is desirable to improve the drug permanence onto the cornea. Here, the micelles containing the drug in a soluble form can produce a concentration gradient over the cornea ensuring passive diffusion over the barrier. The film suffers a transformation from a dry, solid, and stable formulation into an advanced ocular delivery system after contact with the tears [13].

We tried to use the minimum possible amount of materials to prevent interactions between them and the eye, minimize lacrimal production that would dissolve the film in a faster manner, and reduce drug permanence at the target point. Additionally, the use of these films would reduce dosing, compared with conventional eye drops, and improve patient compliance.

The films were prepared using Soluplus and water-soluble polymeric biocompatible and biodegradable materials, with proven no eye-irritation properties. Soluplus is a grafted, biocompatible, biodegradable copolymer, which is a combination of hydrophilic and hydrophobic elements. Several plasticizers were also used to improve flexibility and humidity of the films $[14,15]$.

Films were made applying the solvent-casting technique into a tailor-made mold to assure homogeneity between batches and an even distribution of the drug within the film $[16,17]$. The drug was incorporated in both the base form and the ionic form to test the possible influence of the enhancer in the permeability of the two drug forms.

All the prepared films were preliminary characterized. Those with the most adequate properties for the application pursued were selected for further studies, which comprised the measurement of the content uniformity, stability of the films, in vitro drug release, swelling process, ex vivo permeability studies though isolated porcine cornea and sclera, and microbiological activity assessment.

\section{Materials and methods}

\section{Materials}

$\mathrm{CPXb}$ was bought from Acros Organics (New Jersey, USA), and CPXs was acquired from Cayman Chemical Company (Michigan, USA). Soluplus was kindly donated by BASF SE (Ludwigshafen, Germany). Poly-vinyl alcohol (PVA), polycaprolactone (PCL), gelatin from bovine skin, and chitosan were purchased from Sigma-Aldrich 
(Missouri, USA), and propylene glycol (PG), polyethylene glycol (PEG), hydroxy ethyl cellulose (HEC), and hydroxy propyl methyl cellulose (HPMC) were purchased from Fagron Iberica (Barcelona, Spain). Organic solvents such as DMSO and chloroform were purchased from SigmaAldrich (Missouri, USA). For the phosphate-buffered saline (PBS) used, sodium chloride, potassium chloride, sodium phosphate dibasic, and potassium phosphate monobasic were purchased from Scharlab (Barcelona, Spain). Ultrapure water used throughout the studies was obtained from a Q-POD dispenser (Merck Millipore, Burlington, MA, USA). Acetonitrile for the HPLC mobile phase was purchased VWR International (Radnor, PA, USA). Dialysis membranes (Spectra/Por molecular porous membrane tubing) for in vitro release studies were acquired from Repligen (MA, USA). Corneas were from porcine eyes procured from a local slaughterhouse Mercavalencia (Valencia, Spain).

\section{Methods}

\section{High-pressure liquid chromatography}

A previous published isocratic HPLC-UV method was adapted for the determination of CPX [18]. The mobile phase consisted of a mixture of phosphate buffer $\mathrm{Na}_{2} \mathrm{HPO}_{4}$ $(\mathrm{pH} 3)$ and acetonitrile $(77: 23 \mathrm{v} / \mathrm{v})$. The UV detector was set at $277 \mathrm{~nm}$, flux was $1.0 \mathrm{~mL} / \mathrm{min}$, the volume injection was $50 \mu \mathrm{L}$, and the temperature was maintained at $22{ }^{\circ} \mathrm{C}$. A Kromasil C18 HPLC Column of 5- $\mu$ m particle size, pore size $100 \AA$, and $\mathrm{L} \times$ I.D. $150 \mathrm{~mm} \times 4.6 \mathrm{~mm}$ were used. All the liquids used were of HPLC grade. The CPX retention time was $4.2 \mathrm{~min}$, and the analysis duration was $6.0 \mathrm{~min}$.

\section{Film formulation}

Different polymers, polymer-combinations, and plasticizer proportions were investigated (Tables S1S6 of Supplementary materials). Among them, two different film formulations were chosen based on their organoleptic properties and their controlled release kinetics. Each film was prepared with the molecular form of $\mathrm{CPX}(\mathrm{CPXb})$ and with the hydrochloride salt of CPX (CPXs), resulting in four film candidates. Their composition is described in Table 1.

The polymeric films were prepared in triplicate using the direct dissolution and solvent casting method. First, Soluplus was dispersed in PBS under high magnetic stirring for $1 \mathrm{~h}(700 \mathrm{rpm})$. CPX was added to the dispersion to a final concentration of $0.3 \% \mathrm{w} / \mathrm{v}$, corresponding to the commercially available CPX eye drops and ointment (Ciloxan Alcon Laboratories Pty.
Ltd., Fort Worth, TX, USA). The mixture was kept under medium stirring $(350 \mathrm{rpm})$ for $4 \mathrm{~h}$. In a different beaker, PVA was dissolved in PBS warmed at $90{ }^{\circ} \mathrm{C}$ to facilitate dispersion. After complete dispersion, the volume was corrected to compensate the evaporation. Then, both liquids were mixed and propylene glycol was added at a concentration of $2 \% \mathrm{w} / \mathrm{v}$. Propylene glycol was selected as plasticizer, based on the works of Shirwaikar and Rao, who investigated it for ophthalmic use and proved it as non-toxic to the rabbit eye [19]. The final dispersion was left under medium magnetic stirring overnight. The solution was then left on the bench for at least $3 \mathrm{~h}$, to ensure complete air bubble removal.

For the film casting, a non-stick metal surface coupled with the tailor-made mold was used, thus allowing an even and homogeneous thickness of the films. The mixture was poured into the molds and placed in an oven at $40^{\circ} \mathrm{C}$ for at least $8 \mathrm{~h}$. After complete evaporation of the solvent, the metal surface was left to cool for $1 \mathrm{~h}$ at room temperature and the films were peeled off slowly, wrapped in aluminium foil, and stored in plastic containers at $4^{\circ} \mathrm{C}$.

\section{Film characterization}

Drug content To calculate the amount of drug per square centimetre of film and check the uniformity of the drug distribution within the film, 10 samples of the same size were punched out from different points of the film area (corners and centre), weighted, and placed in beakers with $5 \mathrm{~mL}$ PBS. Five samples of each film were then analyzed by HPLC in triplicate [20]. They were left under magnetic stirring for $2 \mathrm{~h}$ at room temperature to ensure complete dissolution.

Film thickness To measure the thickness of the films, we adapted the Swiss Roll technique [21], originally developed to prepare tissues for paraffin or methacrylate embedding for histological analyses followed by optical microscopy (Nikon Eclipse 50i; Nikon, Tokyo, Japan). Films ( $n=3$ ) were observed using a light microscope with camera (Nikon digital camera, DXM1200C; Nikon, Tokyo, Japan). Film thickness was estimated processing the pictures with the Axiovision software Rel 4.8 (Carl Zeiss Microscopy GmbH, Germany).

Swelling index test A swelling test was performed as drug release from the polymeric matrix is affected by swelling in the presence of water. Five samples of each formulation were weighed, placed into a basket, and inserted into $20 \mathrm{~mL}$ of PBS pH 7.4 at a temperature of $32 \pm 0.5^{\circ} \mathrm{C}$. At pre-determined time intervals $(0.5,1,1.5$, 2 , and $5 \mathrm{~min}$ ), the films were extracted from the solvent 
and weighted after solvent removal. The swelling index $\left(\mathrm{SI}_{t}\right)$ was calculated according to the following equation [13], based on the degree of fluid uptake, as reported by Nanda el at. [22]:

$$
\mathrm{SI}_{\mathrm{t}}=W_{t}-W_{0} \cdot 100
$$

where $W_{0}$ is the initial weight of the sample and $W_{\mathrm{t}}$ is its weight at time $t$.

Dissolution onto porcine eye ex vivo A piece of methylene blue-coloured film (type 2) was punched out and placed onto the surface of ex vivo porcine eyes $(n=3)$. Every $120-150 \mathrm{~s}$, an artificial tear drop is added to the eye surface, trying to mimic the in vivo production. Film dissolution and colouring of the cornea and sclera were observed, as indicative of drug release in situ over $20 \mathrm{~min}$. The test was recorded in a video clip for documentation purposes.

\section{Film stability}

Films were stored for 3 months at room temperature and 4 ${ }^{\circ} \mathrm{C}$, protected from light. They were periodically inspected to check organoleptic property changes or degradation signs. They were also weighed to evaluate possible weight loss. The drug content was also determined by HPLC every week during the first month and two every weeks until the third month.

\section{In vitro release studies}

In vitro release studies were carried out using static Franz-type diffusion cells with an effective diffusion area of $0.385 \mathrm{~cm}^{2}$ and a receptor chamber filled with $3 \mathrm{~mL}$ of PBS (pH 7.4) $(n=5)$. Temperature was maintained at 32 ${ }^{\circ} \mathrm{C}$ throughout the experiment. A Spectra/Por molecular porous membrane was used to separate donor and acceptor compartments. Previously weighed film samples were placed on the membrane in the donor chamber and covered with $150 \mu \mathrm{L}$ of PBS to simulate lacrimal fluids [23]. For comparative purposes, and due to the transformation of the films into gels onto the corneal surface, two hydrogels containing CPXb were prepared as previously described for the films, but without following the casting and drying processes. Both the donor compartment and the sampling port were covered with Parafilm to avoid leakage and solvent evaporation. Samples of $200 \mu \mathrm{L}$ were collected at 1, 2, 3, 4, 5, 6, 21, 22,23 , and $24 \mathrm{~h}$. At every sampling time, the volume was replaced with pre-warmed PBS.
The released CPX was quantified using the same HPLC analytical method described above. The cumulative amounts of CPX versus time were calculated, and the total drug amount released was plotted versus time. The release profiles were fitted to the KorsmeyerPeppas controlled-release model [20].

\section{Ex vivo permeability studies}

The ocular tissues were obtained from freshly sacrificed animals kindly donated by a local slaughterhouse. The eyes were transported immersed in saline solution (sodium chloride $0.9 \%$ ), maintained in an ice bath and used within $2 \mathrm{~h}$ of extraction. The eyes were placed on a clean surface, and the corneas were removed carefully, cutting circumferentially behind the limbus using a scalpel. The separated corneas and scleras were then rinsed with saline and placed in between the donor and receptor chambers of the Franz cells, with the outer surface facing upwards $(n=5)$. The donor chamber was filled with $150 \mu \mathrm{L}$ of PBS to simulate lacrimal fluids [23]. Donor compartments and sampling ports were also covered with Parafilm to avoid leakage and solvent evaporation. About $200 \mu \mathrm{L}$ samples were collected every hour for a period of $6 \mathrm{~h}$. Each time, the sample volume was replaced with the same volume of pre-warmed PBS. It should be noted that the permeability properties of the tissues are lost a few hours after excision [24]. The CPX concentration in the samples was analyzed using the same HPLC analytical method described above. Commercially available eye drops (Ciloxan Alcon Laboratories Pty. Ltd., Fort Worth, TX, USA) were used as a positive control.

The cumulative amount of CPX permeated $\left(M_{n}\right)$ per area was calculated using the following equation (1):

$M_{n}=V_{r} C r_{(n)}+\sum_{x=1}^{x=n} V_{s_{(x-1)}} \mathrm{Cr}_{(x-1)}$

in which, $n$ is the sampling time point; $V_{r}$ and $V_{s}$ are the volumes $(\mathrm{mL})$ of the receptor chamber and of the samples collected at the nth time point, respectively; and $\operatorname{Cr}(n)$ is the concentration of the drug in the receptor chamber medium at the $n$ time point $(\mu \mathrm{g} / \mathrm{mL}) . M_{n}$ was fitted by linear regression and plotted versus time [7].

The steady state flux $(J)$ and the lag time of CPX were determined based on the slope of the graph and the $x$-intercept, respectively. The trans-corneal permeability of the drug was calculated by the following equation (1) [25]:

Permeability $\left(P_{\text {app }}\right)=\frac{\text { Steady state flux }(J)}{\text { Donor concentration }\left(C_{\text {sus }}\right)}$ 
The flux was calculated as the slope $(Q / t)$ of the linear section of the amount of drug in the receptor chamber $(Q)$ versus time $(t)$, and $C_{\text {sus }}$ is the initial concentration of CPX in the donor chamber [25]. The results were reported as the mean values \pm standard deviation $(\mathrm{SD})$.

\section{Corneal inspection and drug extraction from cornea and sclera}

After the experiments, all the corneas were visually inspected after the $6 \mathrm{~h}$ test to verify that none of them showed any damage or their appearance was modified, indicating irritation [26, 27].

Afterwards, the corneas or sclera from all permeability studies were collected, rinsed with fresh PBS, and placed in vials with $5 \mathrm{~mL}$ of the mobile phase used for the analysis to extract the remaining drug in the tissue. The vials were left under constant agitation for $24 \mathrm{~h}$. Samples from the supernatants were collected, filtered, and analyzed by HPLC.

\section{Antimicrobial activity}

To ensure the antimicrobial activity of CPX after the formulation process, the films were tested in vitro using 5 microorganism types, related with most common ocular infections [28-31] Staphylococcus aureus (CECT 59), Pseudomonas aeruginosa (CECT 108), Escherichia coli (CECT 45), Proteus mirabilis (CECT 170), and Enterococcus faecalis (CECT 184). Sterile spreaders were used to apply microbial colonies on Mueller-Hinton agar plates. The films were then placed onto the inoculated agar plates, accompanied with a blank film, to check the absence of antimicrobial activity from the polymeric film itself $[32,33]$. A 5- $\mu$ g CPX commercially available disk (Liofilchem, Roseto, Italy) was also used as positive control. Untreated bacterial colonies were used as a negative control. During $24 \mathrm{~h}$ of incubation, growth inhibition areas were observed around the formulations. Antibiotic susceptibility was determined by disk diffusion according to standard microbiological procedures (CLSI, 2010). Resistances to chemotherapeutic agents were deduced from the diameter of the growth inhibition areas, according to the known diameters for susceptibility and resistance provided by Liofilchem Diagnostici (Italy).

\section{Data analysis and statistical analysis}

All data processing was performed in Microsoft Excel 2016 (Redmond, WA, USA) and SPSS version 22.0 (IBM Corp, Armonk, NY, USA). Data are expressed as the mean \pm standard deviation (SD) unless otherwise stated. Statistical differences were determined using the Student $t$ test or two-way ANOVA followed by Bonferroni post hoc analysis, where $p$ values below $5 \%$ were considered significant. Pictures were processed using Axiovision software (Carl Zeiss Microscopy GmbH, Germany). And videos recorded were edited using VSDC Free Video Editor (Flash-Integro, LLC).

\section{Results and discussion}

\section{Validation of the HPLC method}

The HPLC method was validated within the range of $0.625-10 \mu \mathrm{g} / \mathrm{mL}$ and showed acceptable inter- and intra-assay precision, accuracy, and stability. The detection limit (LD) was $0.016 \mu \mathrm{g} / \mathrm{mL}$, and the quantification limit (LQ) was $0.054 \mu \mathrm{g} /$ $\mathrm{mL}$. The coefficient of variation and relative error was $<10 \%$ for all samples, making the method suitable and reliable for the required sample analysis of this work, according to the OCDE guidelines [34].

\section{Film formulations: preparation and characterization}

From all the tested polymers and concentrations (see Supplementary Materials Tables S1-S6), we observed that low polymer concentrations or the use of low molecular weight polymers resulted in soft films, while higher concentrations or higher molecular weight polymers resulted in more viscous solutions which were not adequate to cast films. Modifications in the matrix composition using different polymers/grades or combinations provided the necessary flexibility. From all the prepared formulations, two of them demonstrated the best organoleptic, flexibility, and softness properties, so they were studied further. Up to our knowledge, these films are the first reported films prepared with Soluplus/PVA by the solvent-casting technique, although they are inspired in the ones prepared by Shamma et al. by the freeze-drying method [35]. Film 1 was prepared with Soluplus/PVA/PG in 3.3:6.6:2 (\% w/v), and Film 2, with the proportions 5:10:3 (\% w/v). Both films were prepared with $\mathrm{CPXb}$ and CPXs forms. Films were labelled as: Film 1b, Film 1s, Film 2b, and Film 2s,

Table 1 Composition of the four selected films

\begin{tabular}{llll}
\hline & $\begin{array}{l}\text { Soluplus }(\% \\
\text { w/v })\end{array}$ & PVA $(\% \mathrm{w} / \mathrm{v})$ & PG $(\% \mathrm{w} / \mathrm{v})$ \\
\hline Film 1b & 3.3 & 6.6 & 2 \\
Film 2b & 5 & 10 & 3 \\
Film 1s & 3.3 & 6.6 & 2 \\
Film 2s & 5 & 10 & 3 \\
\hline
\end{tabular}


corresponding $\mathbf{b}$ to $\mathrm{CPXb}$ and $\mathbf{s}$ to $\mathrm{CPXs}$. The composition of the CPX-loaded films is summarized in Table 1. The four films were transparent and homogeneously whitish, probably due to the presence of the Soluplus micelles, as a concentration dependent whitening of water with the addition of the polymer was observed. However, this whitening should not interfere with vision, as the films are intended to be inserted onto the sclera, and not used as contact lenses. The films also presented a smooth surface, good organoleptic properties, and the desired flexibility, manually evaluated by stretching. The thinner the films, the more comfortable they will be for the patient, although these films are intended to dissolve within $<30 \mathrm{~min}$, forming a gel. Thickness was homogeneous all over the films and ranged between $39.41 \pm 0.60$ and $28.54 \pm 0.56 \mu \mathrm{m}$, as it is shown in Table 2 and Fig. 1. To measure the thickness of the films, we adapted the swiss roll technique, originally developed to prepare tissues for paraffin or methacrylate embedding for histological analyses, followed by optical microscopy and combined with the thickness measuring tool AxioVision Software Rel 4.8 (Carl Zeiss Microscopy $\mathrm{GmbH}$, Germany). We had no access to an electronic device to measure thickness, and the manual equipment available at our laboratories was insufficiently accurate for these films. Up to our knowledge, there is no previous use of the swiss roll technique to evaluate polymeric films, but according to our experience, this technique is able to accurately evaluate the thickness of our films all over their surface in the same sample. The results obtained here agree to previous studies of the research group, as the thickness was homogeneous all over the films, showing no significant differences [36]. However, as it happened in the drug content experiments, there was a slight, not significant, trend to obtain thinner parts of the films on the petri-dish outer ring compared to the centre. Therefore, according to our experience, the technique used here is more suitable to obtain homogeneous films.

Even though previous results of our research group used the Petri-dish as mold producing even surfaced films, the tailor-mold fitted on an anti-adherent surface could improve the peel off process and thickness homogeneity. Additionally, the new technique would

Table 2 Drug content $(\mu \mathrm{g})$ of each film $(n=10)$ and film thickness $(\mu \mathrm{m})$.

\begin{tabular}{lcllll}
\hline & \multicolumn{2}{l}{ Drug content $(\mu \mathrm{g})$} & & \multicolumn{2}{l}{ Thickness $(\mu \mathrm{m})$} \\
\cline { 2 - 3 } \cline { 5 - 6 } & Mean $(\mathrm{SD})$ & $\mathrm{CV}(\%)$ & & Mean $(\mathrm{SD})$ & $\mathrm{CV}(\%)$ \\
\hline Film 1b & $76.7 \pm 5.8$ & 5.1 & & $39.41 \pm 0.60$ & 1.5 \\
Film 1s & $61.3 \pm 1.9$ & 3.6 & & & \\
Film 2b & $48.5 \pm 1.76$ & 3.1 & & $28.54 \pm 0.56$ & 1.9 \\
Film 2s & $50.86 \pm 1.3$ & 3.1 & & \\
\hline
\end{tabular}

Mean \pm SD and coefficient of variation $(\mathrm{CV})$ avoid the $24 \mathrm{~h}$ shaking process to homogeneously distribute the gel onto the Petri dish surface, significantly reducing the production process duration [37].

The drug content measured for each film from 10 random sites is also presented in Table 2. As it can be observed from the low variability in drug content $(<10 \%)$, it can be concluded that the preparation process produced homogeneous films all over the film surface.

The selected method of preparation was the solvent casting technique, because it has proven to be an adequate technique to prepare films showing a good and homogeneous drug distribution [38]. Besides, among the several available techniques of film manufacturing, solvent casting is an undoubtedly widely used method mainly due to the straightforward manufacturing process and its low cost [39]. However, one of the main challenges in film formation by a casting process is to assure content uniformity in the formulation. Agglomeration or sedimentation of solid particles or the presence of air bubbles on the surface are often observed due to the drying process. These alterations can lead to homogeneity problems, which were not observed in our approach [40].

The drug distribution results found in these studies are consistent with the previous works from our research group, where the solvent-casting technique [37]. Other authors have prepared CPX films by the solving casting method but using other polymers and with different therapeutic applications, but few of them have measured the homogeneity in drug content. Wu et al. developed mucoadhesive buccal CPX-films for periodontitis, using sodium carboxymethyl cellulose and sodium alginate as polymers, showing good drug loading $(94.50 \pm 0.04$ to $99.69 \pm 0.21 \%)$, but the authors did not measure drug distribution [41]. Salguero et al. developed hybrid composite films based on layered double hydroxide and hyaluronan to deliver CPX for the prophylaxis and treatment of opportunistic infections in wounds. The authors also reported that the solvent-casting process produced a quite homogeneous film, with $\mathrm{CV} \%$ values ranging between 6.6 and $7.3 \%$ in all cases. Moreover, the CPX content they found was similar for all the films prepared [42]. Garcia et al. developed dendronized chitosan films loaded with CPX for wound dressing. Their films showed excellent CPX content uniformity with very low $\mathrm{CV} \%$, indicating that the casting solvent method employed was also successful [43]. All these approaches were also consistent with our findings, demonstrating that the technique employed is adequate and effective.

We had no access to an electronic device to measure thickness, and the manual equipment available at our 
laboratories was insufficiently accurate for these films. Therefore, we decided to adapt the swiss roll technique. Up to our knowledge, there is no previous use of this technique to evaluate polymeric films, but according to our experience, this technique is able to accurately evaluate the thickness of our films all over their surface in the same sample. Results are presented in Fig. 1 and Table 2. The homogeneity was demonstrated as no significant differences were seen. Moreover, the use of the mold presented the slight, not significant, trend to obtain thinner parts of the films on the Petri-dish outer ring compared with the centre in previous studies [37].

Fig. 1 Film thickness measurements. a Film 1 and b Film 2
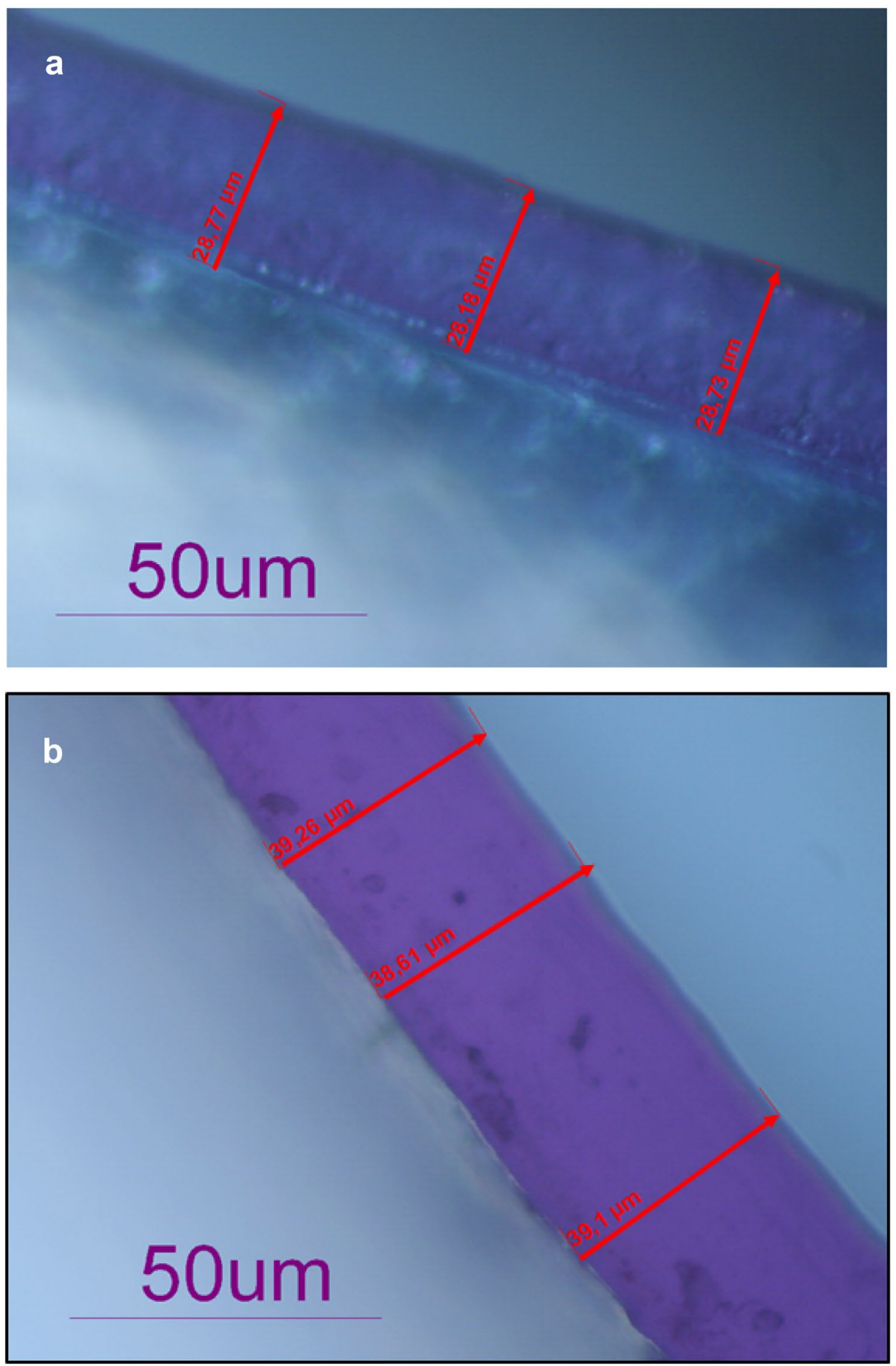
Fig. 2 Swelling index of Films 1 and 2 as a function of time $(n=5)$. Black circle, Film 1 ; white circle, Film 2. The $\mathrm{X}$ sign corresponds to the complete dissolution of the films

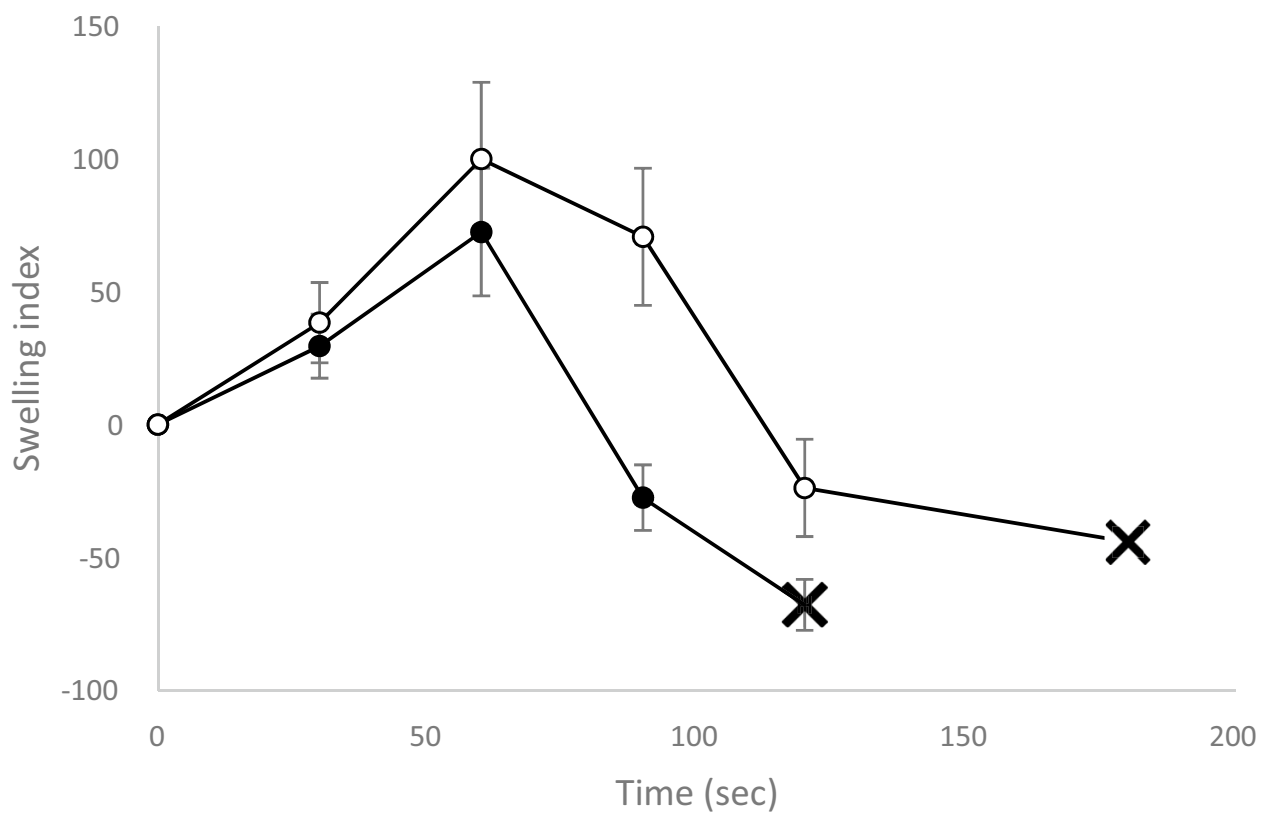

Recent studies confirmed the potential role of nanogels and in situ forming gels in prolonging precorneal residence time and thus improved ocular drug availability [44, 45]. These films adjusted easily to the corneal surface, and they shortly turned into a gel, as they swelled after hydration by the tear fluid, until their complete dissolution (see Fig. 2 and Table 3). In both cases, for Film 1 and 2, prepared without CPX, a wetting process occurs first, in which the swelling index increases, followed by a second erosion process where it decreases. No differences are observed between films during wetting, although the erosion process is significantly slower for Film 2. In our approach, Film 2 dissolves completely in the PBS medium later than Film 1 what was expected due to the higher polymer concentration. A video clip presenting the swelling and erosion of a methylene blue-coloured film (type 1) is also attached to this manuscript.

Our results are comparable with the work of Salguero and coworkers previously cited, who also evaluated the swelling properties of their CPX films for the treatment of opportunistic infections in wounds. The authors concluded that the swelling behaviour of both films was dependent on the medium [42]. They also observed that in all cases, the films did not preserve their form and changed to a gel-like structure at the end of the assay. In our case, we decided to maintain the phosphate buffer saline as representative of the physiological medium. The only study we could find where the combination PVP/Soluplus was used did not report swelling studies, although their reported moisture uptake [35]. The moisture uptake study was conducted at a quite high relative humidity of $75 \%$, which was $<2 \%$ (w/w), indicating good mechanical stability of the film upon storage. These findings are very positive for our film also, as our data show a strong evidence of films dissolution, which is dependent of the water volume. During storage, we expect the films not to degrade, due to the small amounts of environmental water and the possibility to seal the dosage forms with the appropriate conditioning materials. After application of the film onto the eye, the dissolution rate of the film is expected to be slow, due to the small amounts of tears covering the eye-surface. This fact is confirmed in our case through the experiment shown in the video clip 2. Here, we applied a blue-coloured film onto the eye surface and added a drop of artificial tear every 120-150 s. We can observe that the film transforms completely into a gel and the cornea
Table 3 Swelling Index of Films 1 and 2 after 30, 60, 90, 120,180 , and $300 \mathrm{~s}(n=5)$

\begin{tabular}{llrrrll}
\hline & \multicolumn{6}{l}{ Swelling index $( \pm$ SD $)$} \\
\cline { 2 - 6 } & $30^{\prime \prime}$ & $60^{\prime \prime}$ & $90^{\prime \prime}$ & \multicolumn{1}{l}{$120^{\prime \prime}$} & $180^{\prime \prime}$ & $300^{\prime \prime}$ \\
\hline Film 1 & $29.5 \pm 12.0$ & $72.4 \pm 24.0$ & $-27.5 \pm 12.3$ & $-67.8 \pm 9.6$ & - & - \\
Film 2 & $38.3 \pm 15.1$ & $100.0 \pm 28.8$ & $70.6 \pm 25.8$ & $-23.85 \pm 18.3$ & $-44.16 \pm 7.9$ & - \\
\hline
\end{tabular}



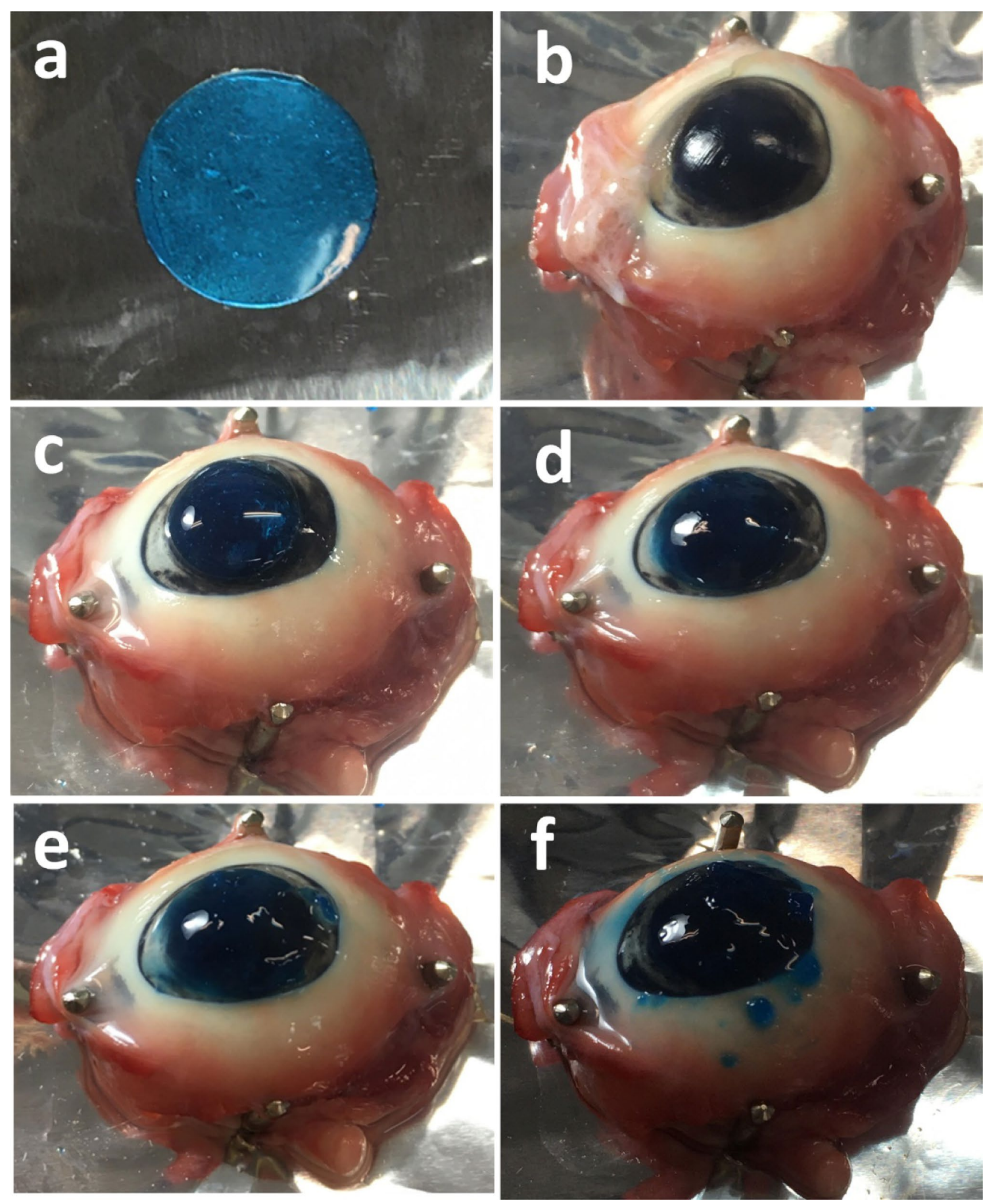

Fig. 3 Dissolution from film to gel onto ex vivo porcine eye. a Film loaded with methylene blue as a dye component, b Eye without film $(t=0 \mathrm{~min})$, c Eye with the hydrated film with artificial tears $(t=1$

min), d Eye with the film-gel $(t=6 \mathrm{~min})$, e Eye with the film-gel $(t=11 \mathrm{~min})$, and $\mathbf{f}$ Eye with the film-gel $(t=20 \mathrm{~min})$ 
and sclera start colouring blue while the film dissolves (see Fig. 3).

\section{Stability studies}

The stability studies comprised an organoleptic evaluation and the analysis of drug content within 3 months. Films were stored in two different conditions, room temperature and $4{ }^{\circ} \mathrm{C}$, preserved from light. The organoleptic properties remained unchanged under the evaluated period. No changes in colour, odour, flexibility, transparency, or any visual damage were observed in the 3-month period. As it can be observed from the data presented here, drug concentration remained stable in all films as demonstrated by non-statistically significant slope of linear correlation between amount of CPX and time over the evaluated period. No significant decrease could be observed respect to the initial concentration. Stability was independent of the film composition and of the drug form. Stability has usually been one of the weaknesses of films due to poor long-term results [46]. Prodduturi et al. managed to develop promising poly (ethylene oxide) films loaded with a poorly soluble drug such as cotrimoxazole through a hot-melt extrusion process. The results obtained were good in terms of characterization and physical properties such as bioadhesion; however, recrystallization processes were observed, and the chemical stability was decreasing significantly and gradually from the moment of its elaboration [47]. Very similar results and limitations were obtained by Senta-Loys et al., who made Orodispersible films loaded with tetrabenazine [48]. However, a long-term stability study should be performed before in vivo animal studies were conducted.

\section{In vitro CPX release form films}

The in vitro release profiles from the films are presented in Table 4. It can be observed that the release profiles are influenced by the CPX-form and the polymer composition,

Table 4 Release parameters of the four films, according to the KorsmeyerPeppas equation $(n=5)$

\begin{tabular}{|c|c|c|c|c|}
\hline & \multicolumn{2}{|c|}{$\begin{array}{l}\text { Korsmeyer-Peppas equation } \\
\text { parameters }\end{array}$} & \multirow[b]{2}{*}{$\% \max$} & \multirow[b]{2}{*}{$R^{2}$} \\
\hline & $N$ & $K$ & & \\
\hline Film 1b & $0.89 \pm 0.06$ & $10.31 \pm 1.8$ & $88.7 \pm 5.2$ & 0.98 \\
\hline Film 2b & $0.68 \pm 0.11$ & $4.75 \pm 0.8$ & $82.6 \pm 9.4$ & 0.99 \\
\hline Film 1s & $0.57 \pm 0.08$ & $23.78 \pm 4.3$ & $108.1 \pm 13.2$ & 0.98 \\
\hline Film 2s & $0.72 \pm 0.06$ & $10.76 \pm 1.6$ & $101.2 \pm 4.9$ & 0.99 \\
\hline Gel 1 & $0.64 \pm 0.09$ & $11.94 \pm 1.9$ & $91.2 \pm 3.2$ & 0.99 \\
\hline Gel 2 & $0.80 \pm 0.05$ & $6.62 \pm 1.1$ & $86.1 \pm 10.2$ & 0.99 \\
\hline
\end{tabular}

as the higher the polymer concentration, the slower the release, and the release was also faster when CPXs were used compared with the CPXb.

In our data, we compare the release differences of $\mathrm{CPXb}$ and CPXs from a hydrophilic matrix, finding differences among them, which was expected. Sink conditions were maintained all over the release studies, so solubility limitations can be discarded from this difference in behaviour. Several authors also refer to the presence of high quantities of water-soluble additives into the formulations, but in our case, the only additive was the plasticizer, whose concentration remained constant in all films.

As we expected, increasing concentrations of polymers produced a slower release than the lower concentrations. CPXs, due to its higher solubility in aqueous medium, were also released faster than $\mathrm{CPXb}$ in all the formulations tested. The gels were also able to control the release of drug but at a lower extent, as the formation of the gels from the films needs some time for hydration. This finding is relevant to understand the improvement of our formulation respect to a semisolid preparation/hydrogel.

According to Siepmann et al., when talking about hydrophilic matrices, when they contact the biological fluids, water penetrates the matrix and dissolves the drug, which then diffuses out of the matrix. However, in this type of matrices, the swelling and polymer dissolution processes must be taken into account to fully understand the release mechanisms. The swelling process produces significant changes in the volume of the system, thus changing the drug concentration. Besides, the mobility of the molecules increases, increasing the drug and water diffusion coefficients. For poorly water-soluble drugs, the drug dissolution process must be taken into account as well, as dissolved and non-dissolved drug coexist within the matrix and it is assumed that drug dissolution within the matrix is fast compared with drug diffusion out of the matrix [49]. Diffusion of penetrants through polymers often does not follow the standard Fickian model, and the controlled drug release is due to the restricted mobility of small drug molecules dispersed or dissolved in the dense macromolecular matrix films [50].

The release rates of the four films have been adjusted to the Korsmeyer-Peppas model finding good correlations $\left(R^{2}>0.98\right)$. The calculated parameters and the fitting parameters are summarized in Table 4 . The release exponent, $n$, is the slope value of $\log Q t / Q_{\infty}$ versus log time curve. When $0.5<n<1.0$, diffusion and non-Fickian transport are implied, associated with the relaxation of polymer chains in the film matrix, due to swelling and erosion [51]. This parameter was in the range of $0.5<n<1.0$ which suggests that the release of CPX from all formulations followed a non-Fickian diffusion mechanism. 
The ability of hydrophilic matrix systems to control the delivery of all types of drugs have been extensively investigated [52, 53]. However, to the best of our knowledge, there is no previously reported release assay with Soluplusbased films. Shama et al. prepared freeze-dried Soluplus/ PVA films for the oral delivery of spironolactone, an insoluble drug for the paediatric use. The authors performed a solubility test, because their aim was to enhance the drug solubility and, at the same time, prepare a solid dosage form convenient for the paediatric use, but not a release one [35].

Alopaeous et al. also designed mucoadhesive buccal films as a mucin-retentive hydrogel scaffold. Their films were prepared with Soluplus, including other polymers with more hydrophilic and known mucoadhesive properties: hydroxypropyl methylcellulose Lycoat [13]. Their film, as in our case, was expected to have a longer residence time on the oral mucosa, but their objective was to achieve a fast release of the micelles to facilitate buccal absorption According to their release aims, authors performed disintegration tests but not a release assay as intended in our work.

The release properties can be controlled by the hydration, swelling, and dissolution processes of the matrix polymers. In the buccal mucosa, the release is therefore enhanced by the amount of water in the absorption area [54]. It should be pointed out here that tear turnover rate in human eyes $\left(0.5-2.2 \mu \mathrm{L} \mathrm{min}^{-1}\right)$ or total tear volume in a healthy eye $(7-9 \mu \mathrm{L})$ [55] could represent sufficient volume of dissolution medium, but in a slow way. Therefore, the release of drug from the formulations in this study is expected to be more prolonged in vivo than as shown by our data. This was demonstrated in the in vivo study carried out by Desai and colleagues. In their study, they obtained differences between the in vivo and in vitro release conditions because of the dissolution volume used to obtain sink conditions. In their in vitro study, the formulation was placed in $2 \mathrm{~mL}$ of dissolution media, whereas in the animal study, the formulation was exposed to just $7-10 \mu \mathrm{L}$ of the tear volume in the ocular cavity. A markedly high release of drug was observed in vitro release conditions, whereas a twofold slower release was observed in vivo [56]. Therefore, the release of CPX from self-dissolvable thin ocular films in this study is also expected to be more prolonged during the in vivo studies, where the tear volume and turnover rate is significantly lower.

\section{In vitro absorption of CPX through cornea and sclera}

The cumulative amounts of permeated CPX per diffusional area of cornea and sclera versus time are presented in Fig. 4 $a$ and $b$, and the calculated permeability parameters are listed in Table 5 (and Tables S7-S8 of the Supplementary Material section). Unfortunately, the low eye viability after excision does not allow prolonged permeability assays, which would be of special interest when testing a controlled release formulation, as it is the case. Besides, this ex vivo surrogate does not mimic real conditions in terms of blinking, tear production, and formulation removal, which can be very important in the final performance.

Our data show that CPX permeability coefficient control is not significantly different among eye-drops, Films $1 \mathrm{~b}$ and $1 \mathrm{~s}$. The differences in the flux depend on differences in CPX concentrations in the donor compartment. This finding implies that the rate-limiting process in both cases is permeability through the cornea and not the release. On the contrary, Film $2 b$ and $2 \mathrm{~s}$ exhibit lower Kp values as consequence of controlled release of the drug.

Previous data reported using Soluplus in ocular permeability showed a significant enhancement of acyclovir solubility, but similar permeability coefficients compared with the free drug in solution. [25]. However, we cannot directly compare the effect to our data because the authors increased drug concentrations, according to the increased solubility produced by Soluplus, while our concentrations remained constant in the hydrogel mixtures to facilitate direct comparisons between formulations. This means that the thermodynamic activity in the donor compartment of the cells containing the films is lower than in the case of the eye-drops. Due to the presence of the solubility enhancer Soluplus, the CPX concentration is

Table 5 Permeability parameters of the four films and control $(n=5)$.

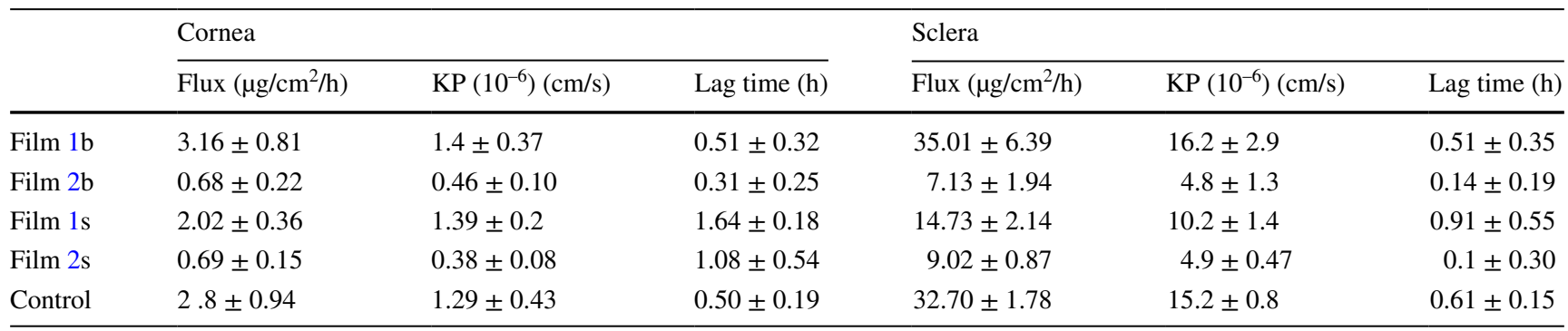

Mean \pm SD 
Fig. 4 a In vitro ocular permeability of CPX from the different films and control through porcine cornea. b In vitro ocular permeability of CPX from the different films and control through porcine sclera. Black circle, Film 1b; white circle, control; white diamond, Film 1s; white triangle,Film 2b; black square, Film $2 \mathrm{~s}$
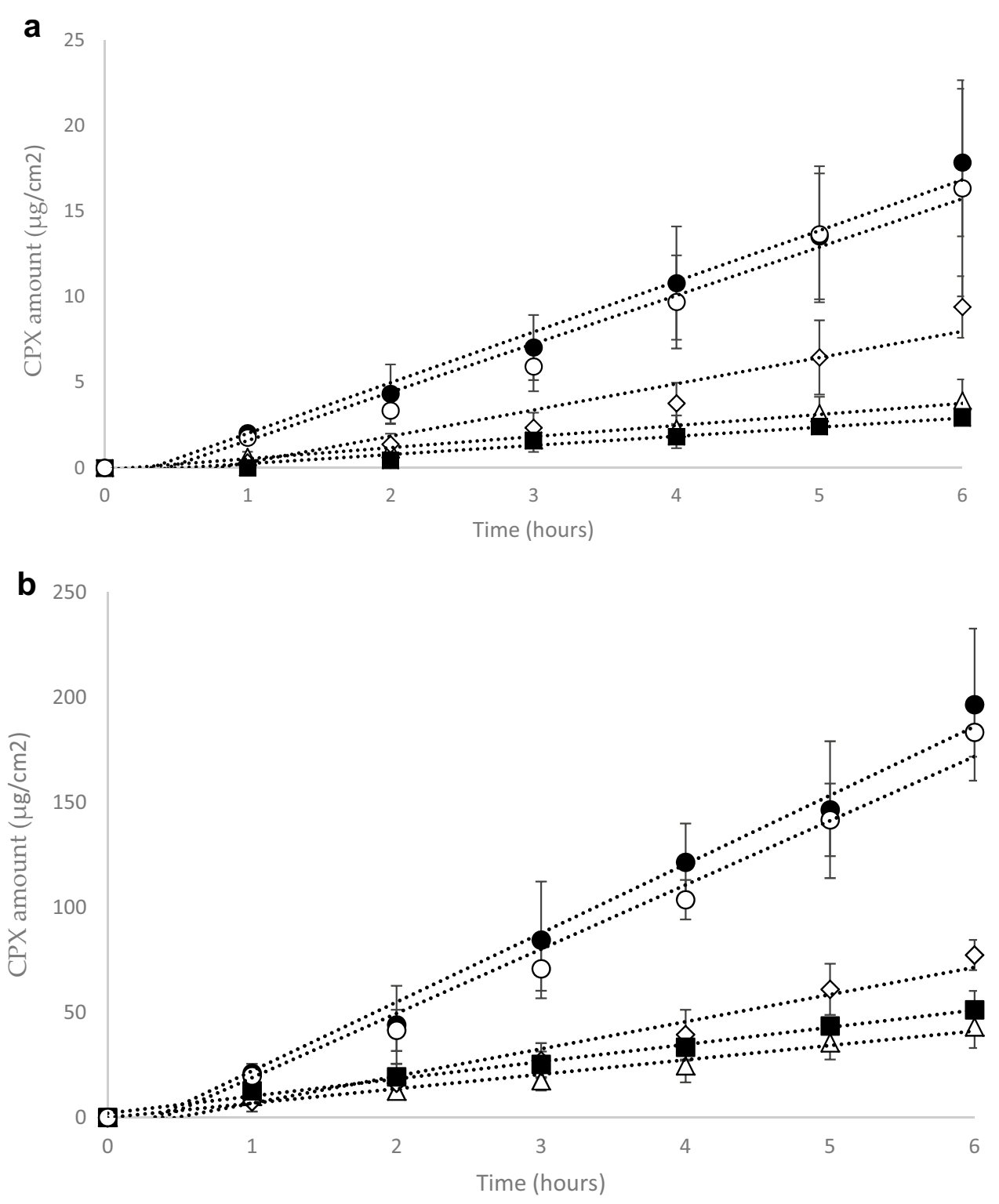

far away from the solubility saturation. The permeability of CPX saturated films could be of interest in further studies, to evaluate the ability of Soluplus to enhance ocular availability, due to the increase in drug concentration in the donor and/or its interactions with the ocular barriers. Despite the great interest of this scientific question, this aim was beyond the purpose of this work at the beginning, as our interest was to evaluate if the films could produce a slow prolonged release to assure continuous permeability through the ocular layers.

On the other hand, as mentioned above, this experimental system has the limitation of keeping the donor formulation in continuous contact with the eye throughout the whole experiment and cannot reproduce the physiological clearance processes. Therefore, the CPX eye-drops are kept continuously in contact with the ocular layers, allowing CPX permeation without interruption. This situation would not happen in the practice, because tear-drainage and blinking would fastly remove the eye-drops from the eye surface, thus interrupting the permeability. That phenomenon would not happen in the case of the films, as they would slowly dissolve and release CPX over a longer time.

The obtained CPX eye-drop permeability on both cornea and sclera correlates well with the reported values in previous studies, thus confirming the goodness of our control and the usefulness of the selected experimental method [57, 58].

Our data also show an increased permeability of CPX through the sclera compared with the cornea, as previously reported. This finding agrees also with the general behaviour in ocular permeability studies. The CPX contained in Film 2, as demonstrated by the release experiments, is made available in a slower manner, thanks to the matrix systems, what is usually reflected in lower permeability ratios in this kind of set-up [59]. 
Fig. 5 Extracted amounts of CPX after the permeability assays through cornea and sclera

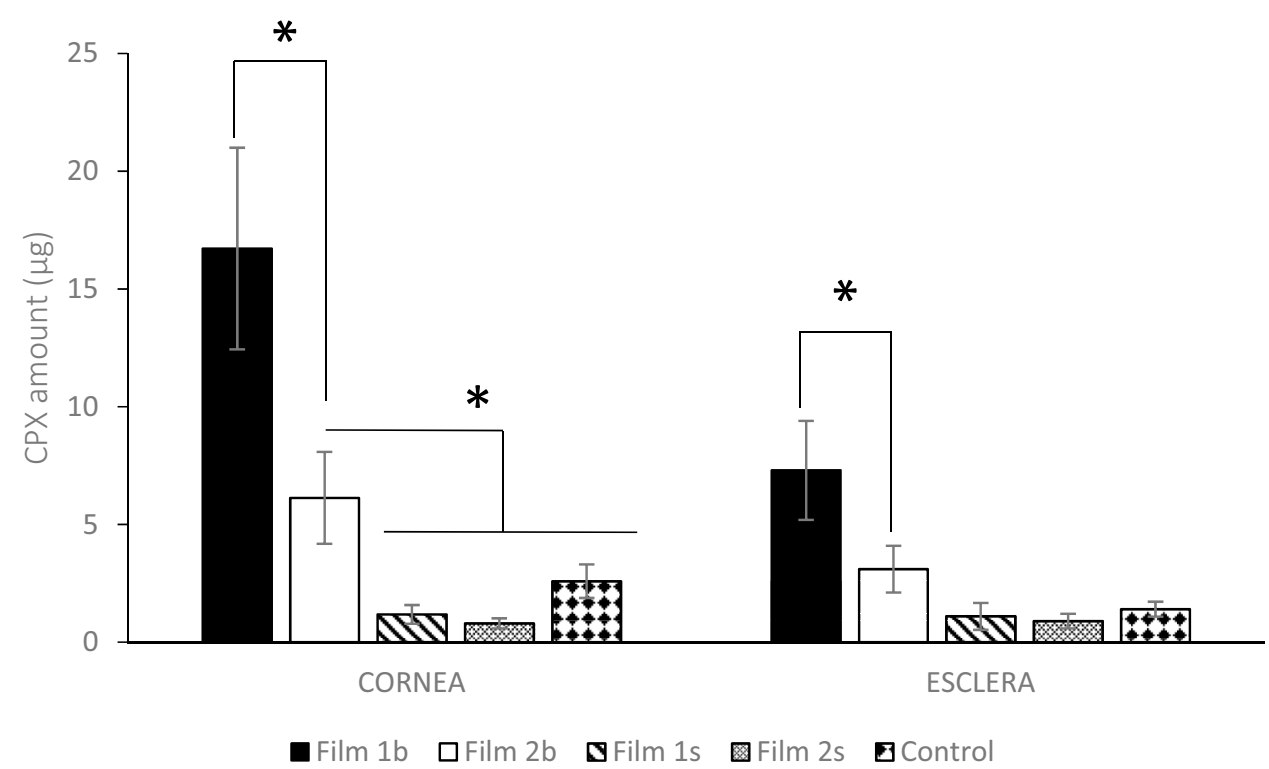

\section{CPX determination in cornea and sclera}

After the permeation experiments, the separated tissues were removed from the Franz cells and visually inspected. No changes in the tissue opacity were observed, indicating absence of irritation.

The effectiveness of a topical antimicrobial agent in the treatment of microbial keratitis is in part dependent on the physicochemical properties of the antimicrobial solution and the structure of the cornea. The concentration of the agent within the cornea is used as a measure of these properties [60]. Therefore, CPX was extracted using the HPLC-mobile phase as solvent. A previous mass balance test and blank extraction test were performed to assure $100 \pm 10 \%$ drug recovery and no interferences with the HPLC-method [61].

Figure 5 represent the amount extracted from cornea and sclera tissues, respectively. The presented data are in agreement with the results found in the permeability experiments. CPX was also remaining in the donor compartments $( \pm 10 \%)$, meaning that the films were able to control drug release beyond the permeability assays period and confirming their ability to reduce dosing. Significantly higher amounts of drug were recovered in both cornea and sclera when the films contained CPX in molecular form compared with those that contained it in salt form. This is due to the fact that the non-ionized forms of drugs have better permeability and retention capacity in the tissues than the ionized forms. Besides, Film 1, due to its lower drug release control, showed a more immediate disposition of higher amounts of drug that logically determines the final amount of drug found after $6 \mathrm{~h}$. The differences observed between the different formulations in the cornea are not so evident in the sclera, probably because the thickness of the tissue is much lower, and therefore, the ability to retain the drug is also smaller. In addition, the structure of the sclera,
Table 6 Sensitivity and resistance results obtained for the films, blank film, and control for the five types of bacteria culture $(\mathrm{S}=$ sensitivity, $\mathrm{R}=$ resistance)

\begin{tabular}{|c|c|c|c|c|c|c|}
\hline & & S. aureus & P. mirabilis & E. faecalis & E. coli & P. aeruginosa \\
\hline \multirow[t]{2}{*}{ Control } & $\mathrm{S}$ & - & + & - & + & + \\
\hline & $\mathrm{R}$ & + & - & + & - & - \\
\hline \multirow[t]{2}{*}{ Film 1b } & $\mathrm{S}$ & + & + & + & + & + \\
\hline & $\mathrm{R}$ & - & - & - & - & - \\
\hline \multirow[t]{2}{*}{ Film 2b } & S & + & + & - & + & + \\
\hline & $\mathrm{R}$ & - & - & + & - & - \\
\hline \multirow[t]{2}{*}{ Film 1s } & S & + & + & - & + & + \\
\hline & $\mathrm{R}$ & - & - & - & - & - \\
\hline \multirow[t]{2}{*}{ Film 2s } & $S$ & + & + & - & + & + \\
\hline & $\mathrm{R}$ & - & - & + & - & - \\
\hline \multirow[t]{2}{*}{ Blank film } & $\mathrm{S}$ & $\mathrm{X}$ & $\mathrm{X}$ & $\mathrm{X}$ & $\mathrm{X}$ & $\mathrm{X}$ \\
\hline & $\mathrm{R}$ & $\mathrm{X}$ & $\mathrm{X}$ & $\mathrm{X}$ & $\mathrm{X}$ & $\mathrm{X}$ \\
\hline
\end{tabular}



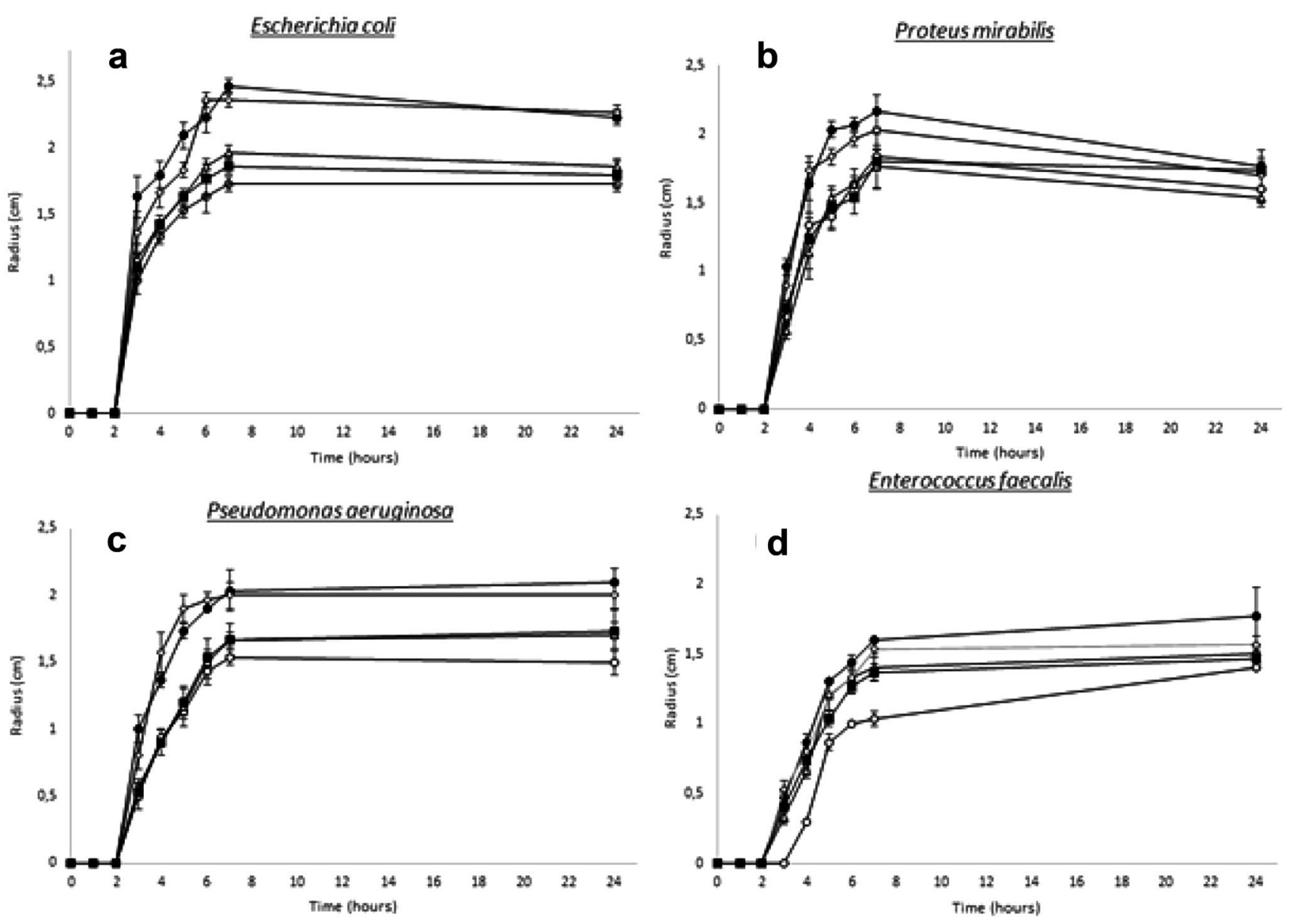

\section{Stophylococcus aureus}

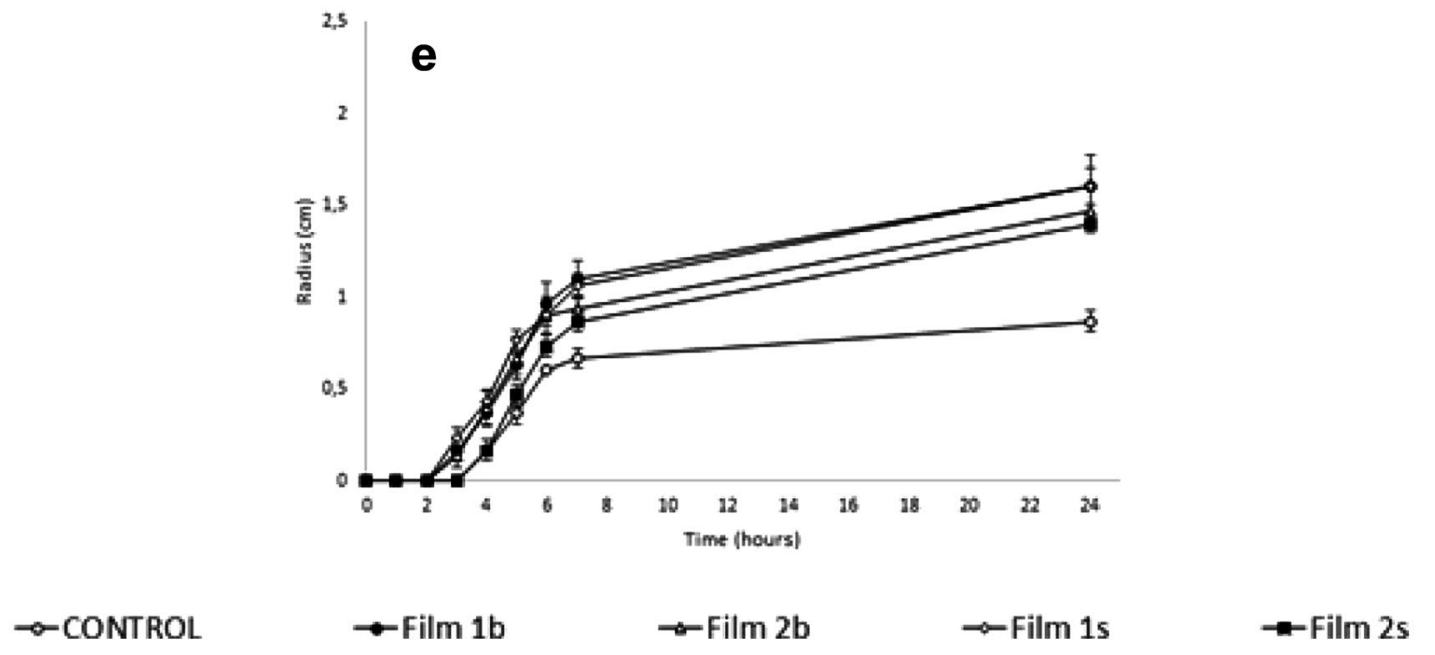

Fig. 6 Radius of inhibition growth of the different microorganism induced by CPX films, the blank film, and CPX control. Black circle, Film 1b; white circle, control; white diamond, Film 1s; white tri- angle, Film 2b; black square, Film 2s. a Escherichia coli; b Proteus mirabilis; c Pseudomonas aeruginosa; d Enterococcus faecalis; e Staphylococcus aureus 

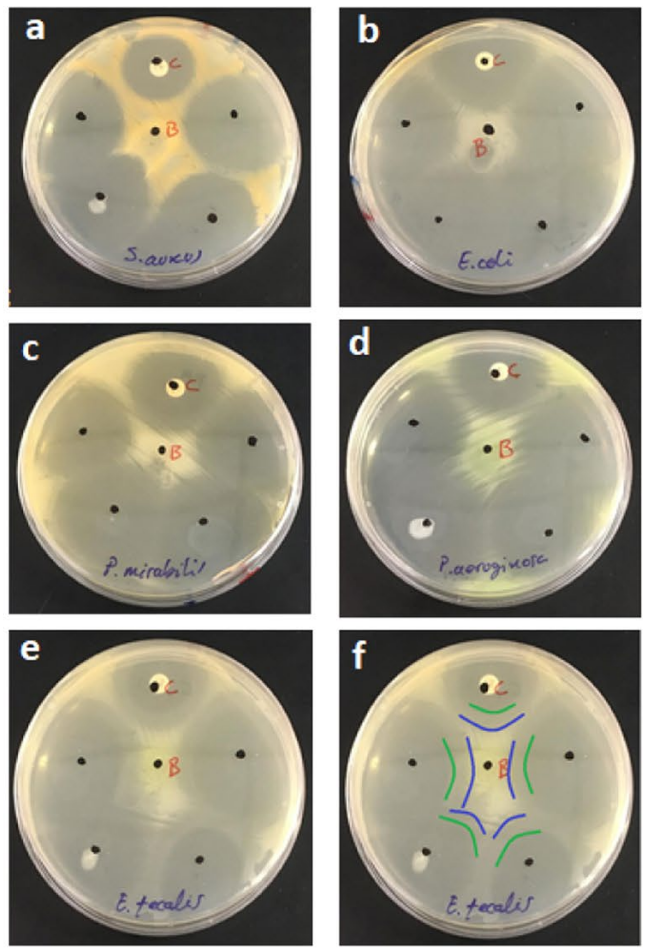
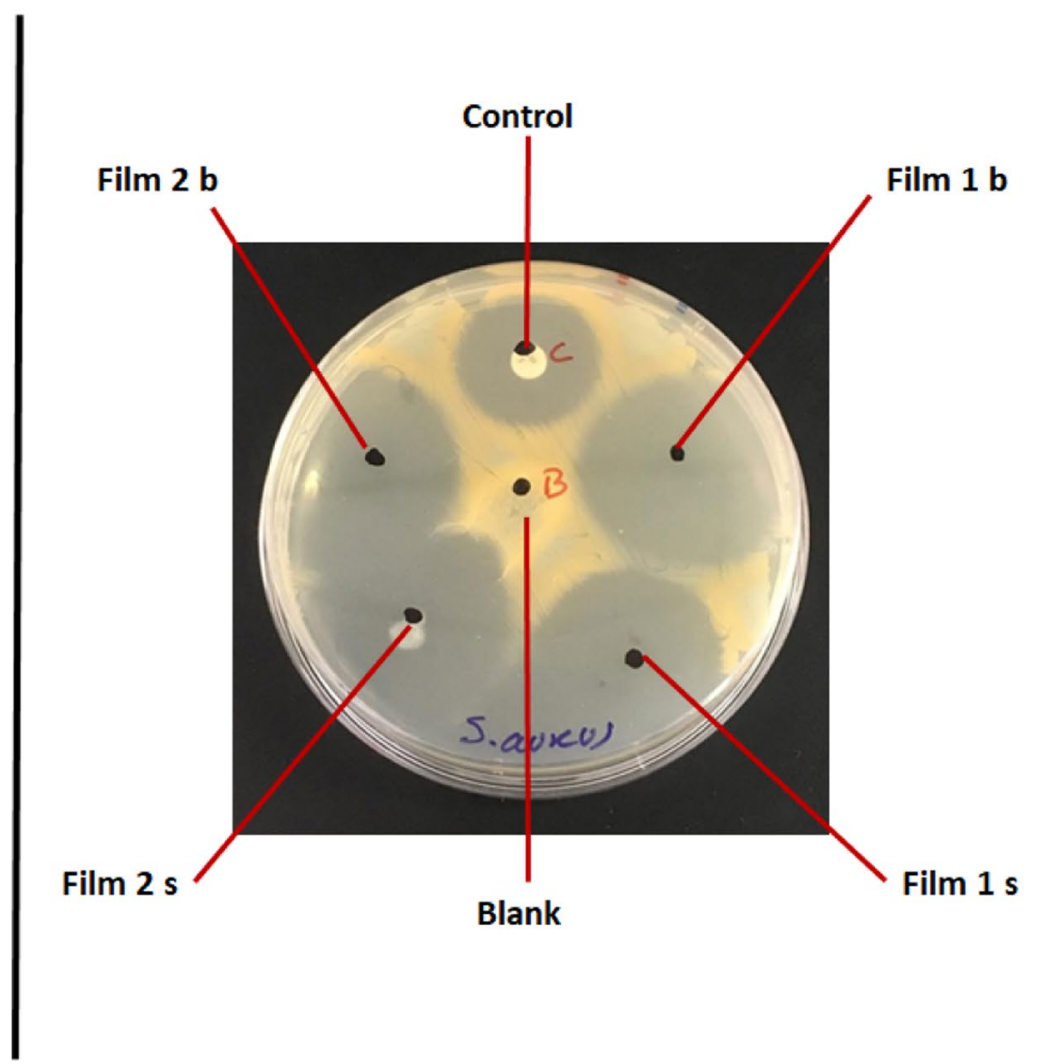

Fig. 7 Inhibition growth of CPX films, blank film, and CPX control in the different microbial cultures $24 \mathrm{~h}$ after application. a Staphylococcus aureus, b Escherichia coli, c Proteus mirabilis, d Pseu-

that facilitates permeability to the posterior parts of the eye, may also contribute to the decreased capacity for drug retention in the tissue [62]. Even though, significant differences can still be observed in CPX retention in the sclera between Film $1 \mathrm{~b}$ and the rest of the formulations.

Balguri et al. studied the ocular disposition of CPX from topical, PEGylated nanostructured lipid carriers in vitro and in vivo. Their in vivo permeability results were consistent with the in vitro observations. CPX accumulation in the different tissues was only assayed in vivo. All the formulations tested and the control solution showed the same trend; the accumulation in sclera was always much lower compared with the cornea [63].

Previous studies with aciclovir loaded Soluplus micelles also showed greater amount of acyclovir accumulated in both cornea and sclera compared with the solution. These findings and our own data allow the hypothesis of a possible influence of the Soluplus as a permeability enhancer for ocular drug delivery, which is worth to investigate in further studies.

\section{Evaluation of the antimicrobial activity of CPX-films}

The agar diffusion assay results showed a considerable antibacterial efficacy of the tested CPX-loaded films, while domonas aeruginosa, e Enterococcus faecalis, $\mathbf{d}$ Enterococcus faecalis (inhibition growth halos highlighted)

no bactericidal activity could be attributed to the blank film. Escherichia coli, Proteus mirabilis, and Pseudomonas aeruginosa were sensitive for the control and all the formulations after $24 \mathrm{~h}$. In certain cases, bacterial regrowth and reduction phenomena of the inhibition areas were observed (Proteus mirabilis). In the case of Staphylococcus aureus, the films were effective even though the commercial control disc inhibition halos presented an insufficient diameter to consider the microorganism as sensitive, according to the established standards (Table 6). Enterococcus faecalis presented a double inhibition halo (see Fig. 7e and f), so the inner mark was used for the subsequent calculations and considerations. This microorganism type was only sensitive for the Film 1b, while the Film 1s showed an intermediate efficacy, since the halo radius was larger than the standard resistance. In general, the highest areas of inhibition were produced by the formulations with the lowest concentration of polymers (Figs. 6 and 7), probably since after their gradual wetting throughout the study, the release occurs more quickly. During the diffusion studies on agar plates, the wetting of the films was much more moderate, and consequently, the release process did not occur in the same way. It is 
probable that, under in vivo conditions, the wetting and dissolution of the films are intermediate between both types of approaches, observing a similar antimicrobial effect between the two types of films for all the challenged microorganisms.

The efficacy of CPX formulations has been widely reported in the literature, but we considered the importance of antimicrobial resistance to classic antibiotics, especially after the application of anti-COVID-19 measures worldwide, which can easily raise antimicrobial resistances, due to the continuous use of antiseptic agents. Several formulations increased ocular CPX antimicrobial activity, when compared with the eye drops. For example, its encapsulation in cubosomes, which form a bicontinuous lipid bilayer, with a high structural similarity with the microbial cell membranes, enable membrane fusion and allow drug transfer into microbial cells [64]. A copolymer composed of pullulan and polycaprolactone (PCL) was also used to synthesize CPXloaded core-shell nanospheres, which were incorporated into HEMA-based contact lenses. Their bactericidal activity was tested using liquid cultures of Staphylococcus aureus and Pseudomonas aeruginosa, which effectively inhibited the proliferation of the bacteria [65].

The developed ocular films have therefore the potential of once-a-day application in the treatment of ocular infections such as bacterial conjunctivitis. Further studies in animal models would be needed to corroborate the access of the drug to the ocular chambers at pre-selected time points and the absence of local side effects or tissue modifications.

\section{Conclusion}

Self-dissolving films can improve the current treatments for eye infections, as they can deliver the drug with a sustained release profile, achieving an adequate absorption, providing an adequate pharmacological activity against the most common types of microorganisms that cause ocular infections, and presenting adequate organoleptic properties to improve patient acceptance.

Supplementary Information The online version contains supplementary material available at https://doi.org/10.1007/s13346-020-00887-1.

Acknowledgements The authors would like thank the Mercavalencia Slaughterhouse (Valencia, Spain), for the kind donation of the ocular samples.

Author contributions Conceptualization, A.J.G, T.M.G, and A.M; methodology and supervision, T.M.G, H.R, and A.M; formal analysis, A.J.G and A.M; investigation and visualization, A.J.G., D.P, and P.S; resources, A.M, H.R.; writing—original draft preparation, A.J.G, D.P., and A.M; writing - review and editing, all authors; funding acquisition, A.M. (A.J.G, Antonio José Guillot; D.P, Dimitrios Petalas; P.S.
Paraskevi Skondra; H.R, Hortensia Rico; T.M.G, Teresa M Garriges; A.M, Ana Melero).

Funding The authors would like thank the Grant number "Competitiveness-FEDER (SAF2017-85806-R)" from the Spanish Ministry of Economy; the grant number "Proyecto emergente GV2015054" from the Valencian Government: Conselleria d'Educacio, cultura I Sport of the Generalitat Valenciana; and the UV-19-INV_AE19 project of the University of Valencia, for the economic support of this work; the University of Valencia: Programa Accions Especials 2019, the Support Centre for Scientific Research at the University of Valencia.

Data availability Data collected regarding this work are presented in the manuscript and Supplementary Materials. All Illustrations were created with Biorender.com.

\section{Compliance with ethical standards}

Ethics approval and consent to participate All the experiments comply with the Spanish current laws, including ethical approval and informed consent. No animal or human studies were carried out by the authors for this article.

Competing interests The authors declare that they have no conflict of interest. The authors alone are responsible for the content and writing of this article.

Consent for publication All authors have read and agreed to the published version of the manuscript.

\section{References}

1. Pascolini D, Mariotti SP. Global estimates of visual impairment: 2010. Br J Ophthalmol. 2012;96(5):614-8.

2. Bhattacharjee A, Das PJ, Adhikari P, Marbaniang D, Pal P, Ray S, et al. Novel drug delivery systems for ocular therapy: with special reference to liposomal ocular delivery. Eur J Ophthalmol. 2019 Jan;29(1):113-26.

3. Hughes PM, Olejnik O, Chang-Lin J-E, Wilson CG. Topical and systemic drug delivery to the posterior segments. Adv Drug Deliv Rev. 2005;57(14):2010-32.

4. Chen H, Jin Y, Sun L, Li X, Nan K, Liu H, et al. Recent developments in ophthalmic drug delivery systems for therapy of both anterior and posterior segment diseases. Colloid Interface Sci Commun. 2018;1(24):54-61.

5. Gaudana R, Ananthula HK, Parenky A, Mitra AK. Ocular drug delivery. AAPS J. 2010;12(3):348-60.

6. Dastjerdi MH, Sadrai Z, Saban DR, Zhang Q, Dana R. Corneal penetration of topical and subconjunctival bevacizumab. Invest Ophthalmol Vis Sci. 2011;52(12):8718-23.

7. Tatke A, Dudhipala N, Janga K, Soneta B, Avula B, Majumdar S. Melt-cast films significantly enhance triamcinolone acetonide delivery to the deeper ocular tissues. Pharmaceutics. 2019;11(4):158.

8. Kotreka UK, Davis VL, Adeyeye MC. Development of topical ophthalmic In Situ gel-forming estradiol delivery system intended for the prevention of age-related cataracts. PLoS One. 2017 Feb $21 ; 12(2)$.

9. Tatham AJ, Sarodia U, Gatrad F, Awan A. Eye drop instillation technique in patients with glaucoma. Eye (Lond). 2013;27(11):1293-8. 
10. Ritch R, Jamal KN, Gürses-Ozden R, Liebmann JM. An improved technique of eye drop self-administration for patients with limited vision. Am J Ophthalmol. 2003;135(4):530-3.

11. Di Colo G, Burgalassi S, Chetoni P, Fiaschi MP, Zambito Y, Saettone MF. Gel-forming erodible inserts for ocular controlled delivery of ofloxacin. Int J Pharm. 2001;215(1-2):101-11.

12. Saettone MF, Salminen L. Ocular inserts for topical delivery. Adv Drug Deliv Rev. 1995;16(1):95-106.

13. Alopaeus JF, Hellfritzsch M, Gutowski T, Scherließ R, Almeida A, Sarmento B, et al. Mucoadhesive buccal films based on a graft co-polymer-a mucin-retentive hydrogel scaffold. Eur J Pharm Sci. 2020;15(142):105142.

14. Gore AV, Pujara CP, Graham RS, Gulmezian M, Prinn K, Srikumar R. Ophthalmic compositions comprising polyvinyl caprolactampolyvinyl acetate-polyethylene glycol graft copolymers [Internet]. US9579385B2, 2017 [cited 2020 Oct 1]. Available from: https:// patents.google.com/patent/US9579385B2/en

15. Adams ML, Lavasanifar A, Kwon GS. Amphiphilic block copolymers for drug delivery. J Pharm Sci. 2003;92(7):1343-55.

16. Adelli GR, Balguri SP, Bhagav P, Raman V, Majumdar S. Diclofenac sodium ion exchange resin complex loaded melt cast films for sustained release ocular delivery. Drug Deliv. 2017;24(1):370-9.

17. Balguri SP, Adelli GR, Tatke A, Janga KY, Bhagav P, Majumdar S. Melt-cast noninvasive ocular inserts for posterior segment drug delivery. J Pharm Sci. 2017;106(12):3515-23.

18. Vella J, Busuttil F, Bartolo NS, Sammut C, Ferrito V, SerracinoInglott A, et al. A simple HPLC-UV method for the determination of ciprofloxacin in human plasma. J Chromatogr B Analyt Technol Biomed Life Sci. 2015;1(989):80-5.

19. Shirwaikar A, Rao PG. Ophthalmic irritation potential of propylene glycol. Indian J Pharm Sci. 1995;57(3):109-12.

20. Bassi P, Kaur G. Polymeric films as a promising carrier for bioadhesive drug delivery: development, characterization and optimization. Saudi pharmaceutical journal: SPJ: the official publication of the Saudi Pharmaceutical Society. 2017;25(1):32-43.

21. Park CM, Reid PE, Walker DC, MacPherson BR. A simple, practical "swiss roll" method of preparing tissues for paraffin or methacrylate embedding. J Microsc. 1987;145(Pt 1):115-20.

22. Nanda A, Sahoo RN, Pramanik A, Mohapatra R, Pradhan SK, Thirumurugan A, et al. Drug-in-mucoadhesive type film for ocular anti-inflammatory potential of amlodipine: Effect of sulphobutyl-ether-beta-cyclodextrin on permeation and molecular docking characterization. Colloids Surf B Biointerfaces. 2018;1(172):555-64.

23. Bao Q, Newman B, Wang Y, Choi S, Burgess DJ. In vitro and ex vivo correlation of drug release from ophthalmic ointments. J Control Release. 2018;28(276):93-101.

24. Majumdar S, Hingorani T, Srirangam R, Gadepalli RS, Rimoldi JM, Repka MA. Transcorneal permeation of L - and D - aspartate ester prodrugs of acyclovir: delineation of passive diffusion versus transporter involvement. Pharm Res. 2009;26(5):1261-9.

25. Varela-Garcia A, Concheiro A, Alvarez-Lorenzo C. Soluplus micelles for acyclovir ocular delivery: formulation and cornea and sclera permeability. Int J Pharm. 2018;552(1-2):39-47.

26. Schrage A, Kolle SN, Moreno MCR, Norman K, Raabe H, Curren R, et al. The bovine corneal opacity and permeability test in routine ocular irritation testing and its improvement within the limits of OECD test guideline 437. Altern Lab Anim. 2011;39(1):37-53.

27. Verstraelen S, Maglennon G, Hollanders K, Boonen F, Adriaens E, Alépée N, et al. CON4EI: Bovine corneal opacity and permeability (BCOP) test for hazard identification and labelling of eye irritating chemicals. Toxicol In Vitro. 2017;1(44):122-33.
28. Teweldemedhin M, Gebreyesus H, Atsbaha AH, Asgedom SW, Saravanan M. Bacterial profile of ocular infections: a systematic review. BMC Ophthalmo. 2017;25:17.

29. Bhatnagar S, Saju A, Cheerla KD, Gade SK, Garg P, Venuganti VVK. Corneal delivery of besifloxacin using rapidly dissolving polymeric microneedles. Drug Deliv Transl Res. 2018;8(3):473-83.

30. Kuriyan AE, Sridhar J, Flynn HW, Smiddy WE, Albini TA, Berrocal AM, et al. Endophthalmitis caused by Enterococcus faecalis: clinical features, antibiotic sensitivities, and outcomes. Am J Ophthalmol. 2014;158(5):1018-23.

31. Borgman CJ. Proteus mirabilis and its role in dacryocystitis. Optom Vis Sci. 2014;91(9):e230-235.

32. Falomir P, Rico H, Gozalbo D. Enterobacter and Klebsiella species isolated from fresh vegetables marketed in Valencia (Spain) and their clinically relevant resistances to chemotherapeutic agents. Foodborne Pathog Dis. 2013;10(12):1002-7.

33. Rico H, Gozalbo D, Sebastia C, Falomir MP. Enterobacter cloacae in fresh vegetables: a potential carrier of antibiotic resistances to consumers. Food Studies: An Interdiscip J. 2013;2(3):1-7.

34. OCDE. guideline-bioanalytical-method-validation_en.pdf [Internet]. Available from: https://www.ema.europa.eu/en/documents/scientificguideline/guideline-bioanalytical-method-validation_en.pdf

35. Shamma R, Elkasabgy N. Design of freeze-dried Soluplus/ polyvinyl alcohol-based film for the oral delivery of an insoluble drug for the pediatric use. Drug Deliv. 2016;23(2):489-99.

36. Melero A, Garrigues TM, Alós M, Kostka KH, Lehr CM, Schaefer UF. Nortriptyline for smoking cessation: release and human skin diffusion from patches. Int $\mathrm{J}$ Pharm. 2009;378(1-2):101-7.

37. Melero A, Garrigues TM, Almudever P, Villodre AMN, Lehr CM, Schäfer U. Nortriptyline hydrochloride skin absorption: development of a transdermal patch. Eur J Pharm Biopharm. 2008;69(2):588-96.

38. De Mohac LM, Caruana R, Cavallaro G, Giammona G, Licciardi $M$. Spray-drying, solvent-casting and freeze-drying techniques: a comparative study on their suitability for the enhancement of drug dissolution rates. Pharm Res. 2020;37(3):57.

39. Karki S, Kim H, Na S-J, Shin D, Jo K, Lee J. Thin films as an emerging platform for drug delivery. Asian J Pharm Sci. 2016;11(5):559-74.

40. Perumal VA, Govender T, Lutchman D, Mackraj I. Investigating a new approach to film casting for enhanced drug content uniformity in polymeric films. Drug Dev Ind Pharm. 2008;34(10):1036-47.

41. $\mathrm{Wu} \mathrm{W}$, Chen $\mathrm{W}$, Jin $\mathrm{Q}$. Oral mucoadhesive buccal film of ciprofloxacin for periodontitis: preparation and characterization. Trop J Pharm Res. 2016;15(3):447-51.

42. Salguero Y, Valenti L, Rojas R, García MC. Ciprofloxacinintercalated layered double hydroxide-in-hybrid films as composite dressings for controlled antimicrobial topical delivery. Mater Sci Eng C Mater Biol Appl. 2020;111:110859.

43. García MC, Aldana AA, Tártara LI, Alovero F, Strumia MC, Manzo RH, et al. Bioadhesive and biocompatible films as wound dressing materials based on a novel dendronized chitosan loaded with ciprofloxacin. Carbohydr Polym. 2017;1(175):75-86.

44. Wang G, Nie Q, Zang C, Zhang B, Zhu Q, Luo G, et al. Self-assembled thermoresponsive nanogels prepared by reverse micelle positive micelle method for ophthalmic delivery of muscone, a poorly watersoluble drug. J Pharm Sci. 2016;105(9):2752-9.

45. Bhatt $P$, Narvekar P, Lalani R, Chougule MB, Pathak Y, Sutariya $\mathrm{V}$. An in vitro assessment of thermo-reversible gel formulation containing sunitinib nanoparticles for neovascular age-related macular degeneration. AAPS PharmSciTech. 2019;20(7):281.

46. Siepmann J, Siepmann F. Stability of aqueous polymeric controlled release film coatings. Int J Pharm. 2013;457(2):437-45. 
47. Prodduturi S, Manek RV, Kolling WM, Stodghill SP, Repka MA. Solid-state stability and characterization of hot-melt extruded poly(ethylene oxide) films. J Pharm Sci. 2005;94(10):2232-45.

48. Senta-Loys Z, Bourgeois S, Pailler-Mattei C, Agusti G, Briançon S, Fessi H. Formulation of orodispersible films for paediatric therapy: investigation of feasibility and stability for tetrabenazine as drug model. J Pharm Pharmacol. 2017;69(5):582-92.

49. Siepmann J, Kranz H, Peppas NA, Bodmeier R. Calculation of the required size and shape of hydroxypropyl methylcellulose matrices to achieve desired drug release profiles. Int J Pharm. 2000;201(2):151-64.

50. Edwards DA. Non-fickian diffusion in thin polymer films. J Polym Sci, Part B: Polym Phys. 1996;34(5):981-97.

51. Yoshida CMP, Bastos CEN, Franco TT. Modeling of potassium sorbate diffusion through chitosan films. LWT - Food Sci Technol. 2010;43(4):584-9.

52. Mahajan HS, Deshmukh SR. Development and evaluation of gel-forming ocular films based on xyloglucan. Carbohydr Polym. 2015;20(122):243-7.

53. Tighsazzadeh M, Mitchell JC, Boateng JS. Development and evaluation of performance characteristics of timolol-loaded composite ocular films as potential delivery platforms for treatment of glaucoma. Int J Pharm. 2019;20(566):111-25.

54. Smart JD. Buccal drug delivery. Expert Opin Drug Deliv. 2005;2(3):507-17.

55. Bachu RD, Chowdhury P, Al-Saedi ZHF, Karla PK, Boddu SHS. Ocular drug delivery barriers - role of nanocarriers in the treatment of anterior segment ocular diseases. Pharmaceutics. 2018 Feb 27;10(1).

56. Namrata V, Mange NV, Desai MS, Gandhi JK, Shah PJ. In-vitro and in-vivo correlation [IVIVC] for nanoparticulate drug delivery systems. Drug Deliv Lett. 2017;7(3):181-9.

57. Tai MC, Lu DW, Chiang CH. Corneal and scleral permeability of quinolones-a pharmacokinetics study. J Ocul Pharmacol Ther. 2003;19(6):547-54.
58. Loch C, Zakelj S, Kristl A, Nagel S, Guthoff R, Weitschies W, et al. Determination of permeability coefficients of ophthalmic drugs through different layers of porcine, rabbit and bovine eyes. Eur J Pharm Sci. 2012;47(1):131-8.

59. Melero A, Ferreira Ourique A, Stanisçuaski Guterres S, Raffin Pohlmann A, Lehr CM, Ruver Beck RC, et al. Nanoencapsulation in lipid-core nanocapsules controls mometasone furoate skin permeability rate and its penetration to the deeper skin layers. Skin Pharmacol Physiol. 2014;27(4):217.

60. Kaye SB, Neal T, Nicholson S, Szkurlat J, Bamber S, Baddon $\mathrm{AC}$, et al. Concentration and bioavailability of ciprofloxacin and teicoplanin in the cornea. Invest Ophthalmol Vis Sci. 2009;50(7):3176-84.

61. Melero A, Hahn T, Schaefer UF, Schneider M. In vitro human skin segmentation and drug concentration-skin depth profiles. Methods Mol Biol. 2011;763:33-50.

62. Prausnitz MR, Noonan JS. Permeability of cornea, sclera, and conjunctiva: a literature analysis for drug delivery to the eye. J Pharm Sci. 1998;87(12):1479-88.

63. Balguri SP, Adelli GR, Janga KY, Bhagav P, Majumdar S. Ocular Disposition of Ciprofloxacin from topical, PEGylated nanostructured lipid carriers: effect of molecular weight and density of poly (ethylene) glycol. Int J Pharm. 2017;529(1-2):32-43.

64. Alharbi WS, Hosny KM. Development and optimization of ocular in situ gels loaded with ciprofloxacin cubic liquid crystalline nanoparticles. J Drug Deliv Sci Technol. 2020;1(57):101710.

65. Garhwal R, Shady SF, Ellis EJ, Ellis JY, Leahy CD, McCarthy SP, et al. Sustained ocular delivery of Ciprofloxacin using nanospheres and conventional contact lens materials. Invest Ophthalmol Vis Sci. 2012;53(3):1341-52.

Publisher's Note Springer Nature remains neutral with regard to jurisdictional claims in published maps and institutional affiliations. 